\title{
Kambo and its Multitude of Biological Effects: Adverse Events or Pharmacological Effects?
}

\author{
Jan M Keppel Hesselink ${ }^{1,2^{*}}$ \\ ${ }^{1}$ Department of Health, University of Witten/Herdecke, Germany \\ ${ }^{2}$ Institute for Neuropathic Pain, Bosch en Duin, The Netherlands
}

*Corresponding author: Jan M Keppel Hesselink, Professor of Molecular Pharmacology, Department of Health, University of Witten/Herdecke, Germany; Institute for Neuropathic Pain, Bosch en Duin, The Netherlands

\begin{abstract}
Background: Kambo is the name of a secretion of a tropical frog, the Phyllomedusa bicolor or giant leaf frog from the Amazonian forest, which has been used for centuries by local tribes to enhance their hunter skills. Its first tribal use was described in 1925, and included the first effects after administration of the secretion: nausea and vomiting. Since the end of last century Kambo is introduced in Europe and the USA as a 'healing' intervention to cleanse the bodily systems, it is regarded as a 'detox' intervention.
\end{abstract}

Method: We reviewed all available literature related to adverse events and pharmacological effects of the active peptides in Kambo.

Result: The secretion of the frog consists a number of bioactive peptides and within few minutes after intake, nausea, vomiting, facial edema, palpitations and hypotension can occur. In the pharmacological and medical literature, these are reported as transient adverse events, although in essence the reactions are purely pharmacological.

We will present and discuss its adverse events, the pharmacological basis of these events and present contraindications and recommendations for safe use.

\section{Keywords}

Dermorphin, Sapo, Phyllomedusa bicolor

\section{Introduction}

Kambo (or Sapo) is increasingly used in ritual contexts for 'healing' and 'cleansing' purposes, as a 'detox' intervention [1]. Research into the pharmaceutical benefit of the peptides from Kambo, started already in the early 60 s, but did not result in the introduction of new therapeutic principles in the clinic, most probably due to the absence of patent protection.
The effect of the intake of the secretion of the tropical frog Phyllomedusa bicolor (Kambo), was first described in a French anthropological journal, by the missionary Tastevin in 1925 [2] Kambo paragraph on pp (19-20). He spoke about the 'milk of a toad' referred to by the Indians as 'Campon'. Tastevin stated that the South American Indians from the Kachinaua, Kurina, and the Kanamari tribes bound the frog alive, cross-limbed, and placed the frog above a fire. The frog then oozed 'a glue' that the Indians collected on sticks to keep when needed. When a tribe-member became ill, or when he was unsuccessful at hunting, because of a bad principle in the body, that principle could be expelled by the 'Campon'. Early in the morning, before dawn, while still fasting, small scars on arm or stomach are made, with the tip of a glowing stick. Then he 'vaccinates' the wounds with the 'milk' of the toad. Soon after the symptoms started with violent nausea and diarrhea. This led to the bad principle leaving the body. The result was new restored health, or much better results while hunting. Tastevin further explained that the Indians in general take Kambo around 5 am, some only for pleasure, and at 7 o'clock they were completely recovered, and if hunters, went for a hunt.

Nowadays, Kambo is used in a specific neo-shamanic subculture as a healing-intervention, and is referred to as a 'medicine', both by shaman's as well as by naturopathic practitioners administrating it. However, Kambo is still seen in the modern circle of users as a way to cleanse the body and remove toxic influences [3]. 
In Kambo so far sixteen bio-active peptides are isolated: Adenoregulin, bombesin, bombesinnona peptide, a bradykinin derivate, caerulein, deltorphin, neurokinin $B$, phyllomedusin, phyllocaerulein, phyllokinin, phyllolitorin, preprotachykinin $B$, ranatachykinin $A$, sauvagine, T-kinin and urechistachykinin II [4]. The first time Kambo was related to the pharmacology of a number of these peptides was in the early 90s [5].

\section{Kambo Ritual: A 'Medicine' and its Effects}

The ultimate goal of the modern neoshamanic Kambo ritual is to achieve 'healing' and 'cleansing' of body, emotions and spirit [1,3]. A Kambo ritual in general starts with drinking around 1 liter of water or cassava soup, and subsequently the therapist or Kambo practitioner, creates a number of small burns via a glowing timber, often around 3-5, traditionally at ankle or upper arm. After scraping away the blister skin, the secretion is applied on the wound, and reaches the lymphatic system and subsequently quickly the bloodstream. The first symptoms reported are a rush of heat, redness of the face, and quickly emerging nausea and vomiting, dizziness, and edema of the face sometimes follows within minutes. Basically, the entire picture after the application can consist of suddenly feeling of warmth, palpitations, rapid pulse, flushed red skin, or paleness, feeling like a lump in the throat or difficulty swallowing, abdominal pain, nausea, vomiting, diarrhea, runny nose and tears, swollen lips, eyelids or face, and rarely a swollen tongue or throat. In general, the duration of the entire symptom-complex is mostly 5-30 minutes and very rarely it lasts for several hours.

Clinicians will most probably define this above described symptom-complex as an anaphylactic shock. However, all these symptoms can be attributed to the pharmacological activity of the peptides of Kambo, and thus the symptom-complex seems not to be anaphylactic of nature, but directly related to its pharmacological effects.

\section{Kambo: Reported Adverse Events}

The first 'adverse events' reported where in the paper from 1925 from Tastevin, where he reported nausea and vomiting. We use the term 'adverse events', however, the effects are sought for by the ones delivering (the practitioners) and receiving Kambo. Although the characteristics of the effects (e.g. nausea, vomiting) are in general seen as aversive, during the Kambo ritual they are considered mandatory, because these symptoms are indicating for the user the cleansing of the body from either bad influences or toxins.

Labate, et al. pointed out there is quite some confusion in the field and references to the use of a "wrong frog," or to misuse of Kambo inducing severe adverse events or even death [6]. Both In groups of users as well as under scholars there exists confusion how to differentiate between the Phyllomedusa bicolor and a certain toxic toad from the genus Chaunus. Labate, et al. further referred to two deaths supposedly caused by Kambo: One in 2008 in Pindamonhanga (São Paulo), and the other in Chile in 2009. Further information on these cases in the paper is absent, so we cannot draw any conclusion so far from these early cases.

According to Peter Gorman, a Kambo specialist who re-discovered the use of Kambo in the early 90s, it might be that there also were some fatal cases in the USA due to drinking far too much water before and/or after the ritual [7]. We will now address adverse events of Kambo, as reported in peer reviewed PubMed indexed Journals.

Den Brave, et al. were the first to report some scars on the shoulder of a patient, without discussing or presenting any case of adverse events [8]. The authors referred to the Kambo use as part of a 'purification ritual'. Within minutes, according to Den Brave, et al. heart throbbing, sweating and nausea arises that leads immediately to severe vomiting. After a few more minutes, the effects disappear. The paper contains a number of misconceptions, such as that shaman's deliver the treatment, that 'Sapo' means frog in Spanish (it means toad) and some more, due to the fact that the writers probably never saw a ritual, neither read Tastevin's paper from 1925.

However, the paper is correct in not referring to 'adverse events' but rather to 'effects' induced by the many bioactive peptides in Kambo: The peripheral and central effects of the secretion (including tachycardia, dizziness, nausea, vomiting and sedation) are provoked by the high concentration of the bioactive peptides. Phyllocaerulein, phyllomedusin and phyllokinin all lead to vasodilatation and thus induce hypotension, and reflex tachycardia.

Leban, et al. dealt with the emergence of a transient syndrome of inappropriate antidiuretic hormone (SIADH) secretion in a 44-year-old woman, due to the drinking of six liters of water after a Kambo ritual [9]. The ritual was organized by a 'South American shaman living in Slovenia', and Kambo was applied via 5 burns on her shoulder. Within 5 minutes she was reported to be dizzy and confused, and after half an hour she seemed well again. Subsequently she drunk a recommended amount of four liters of water. Three hours later she started vomiting and shivering and developed generalized muscular cramps. Thereafter she drunk another 2 liters of water. Nine hours after the start of the ritual, she was found to be nauseated, confused, agitated, dysarthric, tremulous and ataxic and painful muscular cramps in arms and legs.

On the way to hospital a generalized convulsion was witnessed by the emergency physician. Laboratory findings plasma hypo-osmolality (251 mosmol/kg), hyponatremia (116 mmol/L), elevated urine osmolality (523 mosmol/ $/ \mathrm{kg}$ ) and high urine sodium concentration 
(87 mmol/L), all pointing towards a SIADH. Treatment with $0.9 \%$ sodium chloride at a rate of $100 \mathrm{ml} / \mathrm{h}$ and a restriction of water intake was initiated, one day later she was awake and orientated. The case was complicated by rhabdomyolysis. A similar case is reported in literature in a 22-year-old man, who also drunk 6 liters of water within some hours. He also he showed progressive psychiatric and neurological signs including restlessness and convulsions [10]. This symptoms case seems not to deal with a result of Kambo, the symptoms all suggest that the SIADH was solely responsible for the symptomatology, as Kambo actually only induced some early on very light and transient symptoms (dizziness and confusion). Given the absence of nausea and vomiting it very well may be that the concentration of peptides in this Kambo sample was very low, or it was mixed with too much water.

Pogorzelska and Tapiński presented a 34-year-old overweight man with a long history of alcohol and Cannabis use [11]. He was admitted to hospital due to icterus, skin itching, weakness, and pain in the upper abdomen. Patient wanted to stop alcohol and Cannabis use and started Kambo applications once a week to assist the process. Laboratory data: Signs of a transient hepatitis. Patient returned home after 10 days in good condition with normalized laboratory functions.

Aquila, et al. described a sudden death of a 42-yearold overweight man with signs of coronary pathology [12]. He probably self-administered Kambo and was found dead shortly thereafter. It was suggested that in this case perhaps the hypotensive effects of Kambo could have resulted in reduced myocardial perfusion due totachycardia, perhaps leading to a cardiac arrhythmia followed by sudden death.

There were two reports of prolonged symptoms after Kambo administration, such as nausea, vomiting, flushing and facial swelling. These are clearly and directly the pharmacological effects of Kambo. Due to a number of factors such as the purity of Kambo, the concentration of the bioactive peptides, the short 'shelf-life time' of the active components in climate zones with high humidity and temperature, as well as the amount and size of the dots, the bioavailability of the peptides may fluctuate considerably, leading to a somewhat unpredictable intensity and time course of the symptoms $[13,14]$.

Roy, et al. presented Kambo as a ritual based on the 'application of a toxin' and discussed the psychotic decompensation of a Belgian woman, who claimed to be a certified shaman, practicing healing through the utilization of Kambo [15]. She frequently frequency self-administered Kambo, from once per month to up to nine times per month. In the past the police were repeatedly called by the patient about non-existing rapes and shootings in her community. She clearly had a history characteristic for paranoia, including bizarre delusions, but the paper was unclear about any causal relation between the start of Kambo treatment and the evolution of the psychiatric symptoms. She was brought to the hospital in an incoherent mood, suffering from various psychiatric symptoms: Paranoia, anxiety, bizarre delusions, labile mood, and panic attacks. She normalized after the start of risperidone treatment. The authors mistakenly referred to a late effect of Kambo being sedation, based on Daly, et al.; Daly, et al. however do not refer to such symptom [5]. This case report is therefore not at all convincing and cannot support a causal relation between Kambo and the paranoid syndrome. It might very well be that prior to the taking of Kambo the so called 'shaman' already suffered from psychiatric disturbances.

Apart from peer reviewed Journals we found one fatal case in Poland, described, but in the media/web only [16]. The internet site reports the death of a 30-year-old women, who took Kambo. She first started to vomit and subsequently lost consciousness. She was transported by ambulance to the local hospital, where she was connected to an artificial respirator and subsequently died. Apparently, there were also neurological symptoms of intracranial high pressure, cerebral edema and electrolyte disturbances. Therapy, probably with high dose of corticosteroids and supplementation of the electrolyte deficiency did not result in improvement After a few hours, the woman was transferred to the intensive care unit, where she unfortunately died. More details were not provided, and especially lacking was the information whether the patient in question perhaps had an excessive waterintake, resulting in severe hyponatremia before or after the ritual, a recognized cause for SIADH and its cerebral complications [17].

In addition, it is said by some Kambo therapists we interviewed via a closed Facebook community for Kambo practitioners, that there were three additional cases of hyponatremia, in the UK, USA and in Australia. The last one was related to a client dieting on distilled water. All people were saved by sodium infusions and appropriate care in the hospital.

In addition to these cases reported in medical literature, the internet, or by word of mouth from Kambo practitioners via the Facebook community, nowadays many people with little or no experience are ordering Kambo on-line via various internet sites. It seems that at least one case is known where someone was coating the Kambo sticks with egg yolk and selling it as Kambo. Especially in cases of chicken-egg allergies such action can be fatal to a recipient.

Based on these reported adverse events some first recommendations for creating a Kambo ritual as safe as possible are:

1. One should take care not to start with too high a dose. It is recommended the first Kambo session 
to test only a small amount in order to assess the individual sensitivity: One dot.

2. One should be aware that efficacy of Kambo is dependent on many factors, so that one seemingly standard dose might be quite weak in its effects, or extremely strong.

3. Dosing higher induces may induce severe adverse events, and may also lead to health risks making hospitalization necessary.

\section{Pharmacological Effects}

In 1966 Erspamer, et al. reported that the methanol extract of skins from frogs from the family of Phyllomedusae all contain large amounts of powerful bradykinin-like polypeptides [18]. The combination of this high concentration bioactive peptides, and the high potency of the peptides for certain receptors, are inducing the clinical effects, sometimes interpreted as results of an intoxication or a massive allergic reaction, which clearly they are not.

Such peptides have an intense pharmacological effect on smooth muscles and blood vessels leading to hypotension, flushing, palpitations, nausea, vomiting, bile secretion and the angioedema. The peptides responsible for the clinical pattern developing after Kambo intake are especially caerulein, phyllomedusin, phyllokinin and sauvagine. The after effects described as enhanced stamina and better hunting skills might be a result of dermorphine, caerulein or deltorphin, peptides with analgesic properties and affinity for the opiate receptor systems [19].

In 1993 Erspamer, et al. estimated the weight amount of the bioactive peptides entering the body after the application. For one burn, dot or gate as Kambo practitioners call it, the Kambo applied has an approximate weight of $10 \mathrm{mg}$. A single application would contain: Caerulein 320 ug, phyllomedusin 220 ug, phyllokinin $180 \mathrm{ug}$, sauvagine $30 \mathrm{ug}$, deltorphins $53 \mathrm{ug}$ and dermorphin 3 ug [20]. Clearly, if Kambo is harvested from a frog milked in the recent past, the concentrations will be less. Furthermore, there might be differences between Kambo from a male or a female frog.

Caerulein, also known under the name ceruletide, is a decapeptide, stimulating smooth muscle, and increasing digestive secretions from stomach, gall bladder and pancreas [21]. The compound is a cholecystokinin (CCK) analogue, has been introduced in the clinic as a diagnostic tool for gallbladder dyskinesia and pancreas insufficiency. It is used in pharmacological experiments to induce pancreatitis [22].

Phyllomedusin, also a decapeptide, is classified as a tachykinin, just as physalaemin, eledoisin and substance $P(S P)$, all containing the same structural peptide-end [22]. Tachykinins are peptides that are involved in functions of the nervous systems, the cardiovascular and the immune system. Tachykinins interact the three Neurokinin receptor subtype NK1, NK2 and NKB or NK3 [22]. Phyllomedusin appeared to be such a NK1 agonist, with high affinity. It biological effects are related to smooth muscle contraction affecting the salivary glands, tear ducts, tractus intestinalis, and dilation of blood vessels, leading to blood pressure effects [22].

Phyllokinin, another a natural bradykinin analogue resembles bradykinin in its physiological and pharmacological effects- related to lowering blood pressure effects phyllokinin seems three times more active than bradykinin; after trypsin digestion phyllokinin is transformed into bradykinin [23]. The contraction of the ileum and colon was also more powerful compared to bradykinin.

Sauvagine behaves as a corticotropin releasing factor, and mimics the physiological reactions of exposure to stress. In animal models, the compound induces intense, long-lasting hypotensive action accompanied by tachycardia, and accompanied by antidiuresis, decreasing GFR (Glomerular Filtration Rate) and an increasing in tubular $\mathrm{Na}+$ reabsorption [24,25]. Sauvagine binds with to two subtypes of CRF receptor, CRFR1 and CRFR2. It is more potent than CRF (Corticotropic Releasing Factor) at the CFR2 receptor. Clearly many of its physiological functions are related to the stimulation of the hypothalamic pituitary interrenal (HPI) axis, but some effects are quite different from CRF, such as the fact that sauvagine but not CRF produced long-term increases in mesenteric blood flow [26]. Furthermore, it decreases body temperature, the latter being a D2 dopamine receptor-mediated mechanism.

Deltorphins and dermorphins have high affinity to the opiate receptor system and can lead to analgesia [19].

\section{Kambo - Its Contraindications and Consider- ations for its Safe Use}

Kambo has been used for many years in a great number of Western people and given its increasingly use, it is remarkable that only some adverse events have been reported in literature. In closed Facebook groups of Kambo users, more than 6000 participants are registered. Based on these recent case-reports discussed in this paper in section' Kambo: Reported adverse events', it seems wise to exclude from the ritual those suffering from:

\section{- Severe and unstable cardiovascular conditions}

- Hypotensive syndromes such as Shy-Drager

- Psychosis, severe depression and bipolar disorders and severe unstable anxiety disorders

- Pregnancy and breastfeeding

Furthermore, it is recommended to drink some water before a ritual ( $\max$ around 1 liter), and some 
cups of tea after, but not exceeding a total volume of 1.5 liter, as too much water intake may provoke the SIADH syndrome and lead further severe adverse events (cerebral edema).

One should take care not to start with too high a dose, start testing a small dose into assess the individual sensitivity. Be aware that efficacy of Kambo is dependent on many factors; a fixed volume (dose) might be quite weak in its effects, or extremely strong. Dosing higher induces more severe and longer adverse events, and may lead to health risks making hospitalization necessary.

We also recommend to not combine Kambo in the same session with substances such as secretions of Bufo alvarius, Ayahusaca, Jurema, Iboga or other entheogens, and avoid its use in case of polypharmacy.

Further is it recommendable to check whether the practitioner is skilled enough, and has a broad experience with Kambo. Furthermore, it would be recommended to discuss the intention of participating in a Kambo ritual with the family physician. In addition to this, it is recommended to ask some significant other to join if one intend to participate in a ritual.

\section{Conclusion}

Kambo is increasingly used in the West as a shamanistic 'healing' ritual, and many anecdotal cases can be found in the net, claiming reduction of chronic pain and improvement of symptoms in a great many disorders. The administration of Kambo results in a symptom-complex resembling a transient anaphylactic shock. However, it seems that this symptom-complex is not caused by an overreaction of the immune system to an allergen, but it is a pharmacological effect of a number of bioactive neuropeptides, which most probably act synergistically. In Kambo there are many peptides, which can have important contributions in the clinic, such as the analgesic effects of dermorphin or caerulein and the antibiotic effects is some other bioactive peptides. We defined a number of contraindications for its use and recommendation for safe use.

\section{References}

1. Keppel Hesselink JM (2018) Kambô: A Shamanic Medicine - Personal Testimonies. JOJ Case Stud 8.

2. Tastevin C (1925) Le fleuve Muru - Ses habitants. Croyances et moeurs kachinaua. La Geographie. XLIIIXLIV: 403-422 \& 14-35.

3. Keppel Hesselink JM (2018) Kambô: A Shamanistic Ritual Arriving in the West-Description. Risks and Perception by the Users. Int J Psychol Psychoanal 4: 034.

4. Damila Rodrigues de Morais, Rafael Lanaro, Ingrid Lopes Barbosa, Jandyson Machado Santos, Kelly Francisco Cunha, et al. (2018) Ayahuasca and Kambo intoxication after alternative natural therapy for depression, confirmed by mass spectrometry. Forensic Toxicology 36: 212-221.

5. J W Daly, J Caceres, R W Moni, F Gusovsky, M Moos, et al. (1992) Frog secretions and hunting magic in the upper Amazon: identification of a peptide that interacts with an adenosine receptor. Proceedings of the National Academy of Sciences 89: 10960-10963.

6. Labate BC, Lima ECD (2014) Medical Drug or Shamanic Power Plant: The Uses of Kambô in Brazil. Ponto Urbe, Revista do núcleo de antropologia urbana da USP: 15.

7. Peter Gorman, personal communication with the author on 11-11-2018.

8. Den Brave PS, Bruins E, Bronkhorst MW (2014) Phyllomedusa bicolor skin secretion and the Kambô ritual. J Venom Anim Toxins Incl Trop Dis 20: 40.

9. Leban V, Kozelj G, Brvar M (2016) The syndrome of inappropriate antidiuretic hormone secretion after giant leaf frog (Phyllomedusa bicolor) venom exposure. Toxicon 120: 107-109.

10. Yamashiro $M$, Hasegawa $H$, Matsuda A, Kinoshita $M$, Matsumura O, et al. (2013) A case of water intoxication with prolonged hyponatremia caused by excessive water drinking and secondary SIADH. Case Rep Nephrol Urol 3: 147-152.

11. Pogorzelska J, Tapiński TW (2017) Toxic hepatitis caused by the excretions of the Phyllomedusa bicolor frog - a case report. Clin Exp Hepatol 3: 33-34.

12. Aquila I, Gratteri S, Sacco MA, Fineschi V, Magi S, et al. (2018) The Biological Effects of Kambo: Is There a Relationship Between its Administration and Sudden Death? J Forensic Sci 63: 965-968.

13. Li K, Horng H, Lynch K, Smollin CG (2018) Prolonged toxicity from Kambo cleansing ritual. Clin Toxicol (Phila) 2: $1-2$.

14. Kumachev A, Zipursky JS, Weinerman AS, Thompson M (2018) Poisoning from the Kambô ritual. CJEM 20: 962964.

15. Roy R, Baranwal A, Espiridion ED (2018) Can Overuse of Kambô Cause Psychosis? Cureus 10: e2770.

16. http://www.polsatnews.pl/wiadomosc/2016-11-24/ tajemnicza-smierc-kobiety-po-zabiegu-kamboaplikowanie-wydzieliny-z-zaby-coraz-popularniejsze-wpolscel

17. Nathan BR (2007) Cerebral correlates of hyponatremia. Neurocrit Care 6: 72-78.

18. Anastasi A, Bertaccini G, Erspamer V (1996) Pharmacological data on phyllokinin (bradykinyl-isoleucyltyrosine o-sulphate) and bradykinyl-isoleucyl-tyrosine. $\mathrm{Br} \mathrm{J}$ Pharmacol Chemother 27: 479-485.

19. Keppel Hesselink JM (2018) Kambo: A ritualistic healing substance from an Amazonian frog and a source of new treatments. Open J Pain Med 2: 004-006.

20. Erspamer V, Erspamer GF, Severini C, Potenza RL, Barra D, et al. (1993) Pharmacological studies of 'sapo' from the frog Phyllomedusa bicolor skin: A drug used by the Peruvian Matses Indians in shamanic hunting practices. Toxicon 31: 1099-1111.

21. Anastasi A, Erspamer V, Endean R (1967) Isolation and structure of caerulein, an active decapeptide from the skin of Hyla caerulea. Experientia 23: 699-700.

22. Falconieri GE, Anastasi A, Cei JM (1970) Pharmacological observations on phyllomedusin. J Pharm Pharmacol 22: 466-467.

23. Erspamer V, Anastasi A, Bertaccini G, Cei JM (1964) 
Structure and pharmacological actions of physalaemin, the main active polypeptide of the skin of Physalaemus fuscumaculatus. Experientia 20: 489-490.

24. Montecucchi PC, Henschen A, Erspamer V (1979) Structure of sauvagine, a vasoactive peptide from the skin of a frog. Hoppe-Seyler's Z, Physiol Chem 360: 1178.

25. Erspamer V, Erspamer GF, Improta G, Negri L, Castiglione
R (1980) Sauvagine, a new polypeptide from Phyllomedusa sauvagei skin. Naunyn-Schmiedeberg's Arch Pharmacol 312: $265-270$.

26. Lovejoy DA, BalmentRJ (1999) Evolution and physiology of the corticotropin-releasing factor (CRF) family of neuropeptides in vertebrates. Gen Comp Endocrinol 115: 1-22. 